\title{
Model Designing Work Facilities of Brick Creamers Using Biomechanics Approach at UD. Usaha Muda
}

\author{
Cut Ita Erliana, Department of Industrial Engineering, Universitas Malikussaleh, Aceh, Indonesia, \\ cutitha@unimal.ac.id \\ Dahlan Abdullah, Department of Informatics, Universitas Malikussaleh, Aceh, Indonesia, dahlan@unimal.ac.id
}

\begin{abstract}
UD. Usaha Muda is a manufacturing company engaged in the production of bricks, located in Dewantara District, North Aceh Regency. This study aims to redesign work facilities so that they can relieve the forces that occur in each segment of the worker's body and improve work posture. Work activities are carried out in a standing position to print bricks and bend over to move bricks that have been completed to a temporary drying place. This work attitude is not ergonomic or is an unnatural work position that is often caused by work facilities, causing discomfort and pain in body segments. This study begins with the identification of pain complaints with the NBM questionnaire. Furthermore, the calculation of the magnitude of the force that occurs in each segment of the worker's body using a biomechanical approach. The results of the analysis with the NBM questionnaire obtained information on complaints of pain in the largest body segment at the waist. Meanwhile, the results of the force analysis using a biomechanical approach, the greatest value of force in each body segment occurs in the body / waist and thighs. Based on the results of the re-design, the improvement of work facilities with ergonomic principles can reduce the working force on each segment of the body and reduce the risk of muscle complaints by reducing work posture bent on each element of work performed by workers.
\end{abstract}

Keywords: Biomechanics, Bricks, Work Facilities, Design.

Received: $15.11 .2020 \quad$ Accepted: 04.12.2020 $\quad$ Published: 02.01.2021

\section{INTRODUCTION}

Industry is a human effort in combining or managing environmental materials and resources into goods that are beneficial to humans. The home industry is a form of the Indonesian people's economy, if it is developed it will be able to solve the basic problems of development in Indonesia. The brick industry is one type of community business that is carried out by individuals and families.

An industrial work activity is a work system that influences one another. One part of the work system is workers whose work attitude is not ergonomic. This can affect workers in doing their job.

An ergonomic work attitude is an unnatural work position which is often caused by the location of the facilities that are not in accordance with the worker's anthropometry so that it affects the worker's performance in carrying out work. Unnatural work postures such as working postures that are always standing, squatting, bending, lifting and carrying for a long time can cause discomfort and pain in one limb.

Gampong Ule Pulo which is located in North Aceh district, Dewantara District is one of the brick producing areas or industries. Based on observations made at one of the brick craftsmen, namely UD. Usaha Muda Activities are still carried out in a standing position to print bricks and bend over to move the finished bricks to a temporary drying place, this is done within 6 hours of work each day.

From the results of the distribution of the Nordic Body Map (NBM) questionnaire to workers, information was obtained on the occurrence of complaints on the hands (right and left), legs (right and left), and on the waist with the biggest complaints. This is due to the work position that is not ergonomic during production activities, such as standing work and in one event the worker stands on one leg, the removal of bricks that have been printed is done by bending repeatedly.

\section{LITERATURE REVIEW}

Ergonomics is the study of human behavior in relation to their work. The target of ergonomics research is humans when working in the environment. In short, it can be said that ergonomics is the adjustment of work tasks to the condition of the human body, which is to reduce the stress that will be faced. The efforts include 
adjusting the size of the workplace with the dimensions of the body so that it is not tiring, setting temperature, light and humidity to suit the needs of the human body.

There are several definitions stating that ergonomics is aimed at "fitting the Job to the worker", meanwhile the ILO, among other things states, as an applied science of human biology and its relationship with engineering for workers and their work environment, in order to get maximum job satisfaction in addition to increasing their productivity".

Biomechanics is a science that discusses the biomechanical aspects of the movements of the human body. Biomechanics is a combination of mechanics, anthropometry, and basic medical science (biology and physiology). According to Frankel and Nordin, biomechanics uses the concepts of physics and techniques to explain the movements of various parts of the body and the forces that act on the parts of the body in daily activities. According to Caffin and Anderson (1984), occupacional biomechanics is the study of the relationship between workers and their equipment, work environment and others to improve performance and minimize the possibility of injury.

Biomechanics and how it works is the regulation of body posture at work. Different work attitudes will produce different strengths in performing tasks. In this case, biomechanical research measures the strength and physical endurance of humans in doing certain jobs, with certain work attitudes. The aim is to get a better working method, where the maximum physical strength / endurance and the minimum chance of injury. Biomechanics deals with humans in terms of their abilities such as strength, endurance, speed and accuracy. Biomechanics is defined as the application of mechanics to biological systems. Biomechanics is a combination of the disciplines of applied mechanics and the sciences of biology and physiology. Biomechanics concerns the human body and almost all bodies of living things. In biomechanics, the principles of mechanics are used in the drafting, analysis, design and development of equipment and systems in biology and medicine.

The human skeletal system is an organ system that provides physical support to living things. Frame systems are generally divided into three types: external, internal, and liquid base (hydrostatic frames), although hydrostatic truss systems can also be classified separately from the other two types due to the absence of a supporting structure.

The human skeleton is formed from a single or combined bone (such as the skull) which is supported by other structures such as ligaments, tendons, muscles, and other organs. The average adult human has 206 bones, although this number can vary between individuals. While the skeletal function system for the human body.

1. Bones provide support and shape to the body

2. Movement

3. Protection

4. Formation of blood cells (hematopoiesis)

5. Mineral storage (calcium and phosphorus)

6. Adherence of the skeletal muscles

7. Allows organisms to move

The muscular (muscular) system consists of a large number of muscles which are responsible for body movement. Muscles are often known as the "flesh" of the body and are composed of many walls of the body's hollow organs and vessels. Muscle tissue, which accounts for $40 \%$ to $50 \%$ of body weight, is generally composed of contactile cells called muscle fibers. Later, through contraction, the muscle cells will produce movement and do work.

In general, muscles have several characteristics, including: the fibers contain many myofibrils which are composed of contractile myofilaments, the nucleus of muscle cells is well-formed, the cytoplasm is called sarcoplasm, the cell membrane is called sarcolema, the smooth endoplasmic reticulum is called the sarcoplasmic reticulum, and muscle fibers. can enlarge.

1. Muscular System Functions

There are three main functions of muscles, namely: movement, body support, and heat production. Muscles produce movement in the bones to which they are attached, besides that they also support the skeleton and can sustain the body while in a sitting or standing position. Metabolic contraction of muscles will produce heat that can maintain normal body temperature.

2. Characteristics of Muscles

Muscles are active tools of motion because of their ability to contract. Muscles will shorten when they are contracting and lengthen when they are relaxed. Muscle contractions can occur when the muscles are doing 
an activity, whereas muscle relaxation occurs when the muscles are resting. Thus, it can be concluded that muscles have 4 characteristics, namely: contractility, excitability, extensibility, and elasticity.

Skeletal muscles perform muscle work, namely contraction and relaxation. As a result of this contraction and relaxation activity, there will be movement in the body frame. Muscles never work on their own, even to carry out the simplest movements. For example, when picking up a pencil, it requires movement of the fingers and thumbs, wrists, elbows, shoulders and possibly the torso when bending forward. Every muscle must contract and every antagonist muscle must be relaxed for smooth motion. The harmonious work of the muscles is called muscle coordination.

(Wignjosoebroto, 2006) Facility design is an activity to produce facilities consisting of structuring the physical elements, regulating the flow of materials, and ensuring the safety of workers. In fact, the output of the facility design is only the area of the room. The area of the room results from the arrangement of the various components involved in the internal business processes of the company or organization. Facility design activities are analyzing, forming concepts, designing, and realizing systems for the manufacture of goods or services. The basis for the arrangement of facility components is the flow of goods; information flow; working procedures; and workers who will be optimized, both from an economic and technical perspective.

The main elements of facility design are the types of inputs (raw and supporting materials, goods, buyers, foodstuffs,), production or transformation activities (processing and manufacturing, services and buyers, food processing), the resulting output (products and waste, goods purchased, food served). In designing facilities, designers need to pay attention to the three elements above. The designer must understand what is the input, how each input is processed, and what is being produced. Regarding process or transformation activities, designers need to be familiar with the technology. For example, in designing a manufacturing facility, the designer needs to understand the production technology to be used. In other words, the design process really requires a broad insight into the object to be designed.

The Nordic Body Map is a questionnaire used in ergonomics. Another term used besides the Nordic body map is the International Labor Organization (ILO) checklist, however, the Nordic Body Map questionnaire is the most frequently used questionnaire to determine workers' discomfort, and this questionnaire is used the most frequently. because it is standardized and neatly arranged.

The filling of the nordic body map questionnaire aims to find out which parts of the worker's body feel sick either before or after doing work at their respective work stations. This questionnaire uses a picture of the human body which has been divided into nine main parts, namely the neck, shoulders, upper back, elbows, lower back, wrists / hands, waist / buttocks, knees, heels / feet.

Through Figure 1, it can be seen that the parts of the muscles that are experiencing complaints, ranging from discomfort to very painful. By analyzing the nordic body map, it can be estimated the type and level of skeletal muscle complaints by workers. The nordic body map includes the neck, wrists, static back, dynamic back, waist, legs and ankles.

Before this research was conducted, there have been several previous studies related to this research as follows: Rahmadan Syah Saragih (2015) "Biomechanical Analysis of Oil Palm Harvesting Workers with Egrek at PT. Perkebunan Nusantara III (Rambutan Gardens) ".

The process of harvesting oil palm is generally carried out using human labor and using manual harvesting equipment, namely egrek and dodos. The effect caused by the use of this tool is the presence of muscle complaints in harvest workers. This research focuses on harvest workers who specifically use egrek in the process of harvesting oil palm in the plantation area owned by PTPN III Kebun Rambutan. Work attitude in harvesting activities using egrek generally requires a large amount of energy, ranging from $0.78 \mathrm{kcal}$ to 1.40 kcal. In addition, unsupportive work facilities will also cause work fatigue, resulting in decreased productivity of oil palm workers.

The problem of using egrek above was analyzed by using Standard Nordic Qustionare (SNQ) to determine the complaints of pain in the muscles felt by egrek harvest workers. Biomechanical analysis is used to determine the muscle workload that occurs during grunting activity. Then Range of motion (ROM) is used to see the simulation results based on the harvest labor movement category. Then look for the appropriate distance between the harvest laborers and the height of the palm trees. After that, the physical load calculation of the brouha method is carried out to determine the energy that comes out of each harvest worker, which is then given a recommendation to provide intake as a substitute for the lost energy.

The results of the SNQ show that the average harvest laborer experiences severe pain complaints of $12.43 \%$, after which the average energy harvesting worker is 5080 newtons or $1.22 \mathrm{kcal}$ and also the amount of muscle energy for each segment when directing and pulling. egrek. Based on the range of motion, the 
optimum angle for the shoulders and arms is 900 to 1200, the knees and legs are 1650 to 1750 and the back angle is 850 to 950. There is also a comparison of the actual and simulated workload values with the percentage of energy reduction to direct by $22.84 \%$. and attracts $3.83 \%$. After that, the equation is obtained to determine the appropriate distance between harvest workers and oil palm trees, namely $\mathrm{dt}=0.5(\mathrm{Hp}-\mathrm{Hb})+0.36$ where $\mathrm{dt}$ is the distance between trees and harvest workers, $\mathrm{Hp}$ is tree height and $\mathrm{Hb}$ is shoulder height standing harvest laborers. After that, the average calorie loss of harvest workers was $48.6 \mathrm{kcal}$ and was replaced with an adequate food intake in the form of 2 biscuits with a caloric value of $55 \mathrm{kcal}$.

Muchamad Catur Setiawan 2012 "Improvement of Work Posture by Redesigning the Printing Table Using the Reba Method and the Biomechanical Approach (Case Study: PT. Danar Hadi Santosa)". In Solo, there are various kinds of handicrafts that produce batik cloth, one of which is PT Danar Hadi Santosa. The batik fabrics produced by this company include batik cloth from the screen printing process. Based on the observations of making batik printing from the start to the finish, it is known that during the printing process there is discomfort at work, this inconvenience can be seen from the activities that are repeated continuously with a large force load, and the work attitude of the operator is unnatural. for example, the movement of the hand raised and the back that is too bent. From the results of the nordic body map questionnaire, the average complaints of the greatest pain levels include the back, arms and calves.

This study begins with the identification of pain complaints caused by the operator's unnatural work posture, this can be seen from the assessment using the REBA method. In addition, pain complaints are caused by body segments that receive large loads, including on the back, thighs and calves, this can be seen from the calculation of force using the local refferency system (LRS) method. Due to this problem, work posture was improved by redesigning the ergonomics-based printing table.

\section{METHOD}

This type of research used in this research is explanatory research (explanatory research) using a quantitative approach. This study aims to test a theory or hypothesis in order to strengthen or even reject existing theories or research hypotheses. Exploratory research is basic in nature and aims to obtain information, information, data on things that are not yet known. Because it is fundamental, this research is called exploration.

This research was conducted at UD. Young Business in Ule Pulo Village, Dewantara District, North Aceh. The overall research time was carried out from July 2020 which began with the preparation stage of the research proposal preparation until the writing of the research report until December 2020.

The several types of data collected in conducting this research are as follows:

1. Primary data

Primary data is data obtained from direct observations and measurements during research, namely:

a. Muscle complaint data with the NBM questionnaire.

b. The way workers carry out work activities.

c. Worker anthropometric data

d. Work facility data.

e. Secondary data

2. Secondary data is data obtained from company documentation. This secondary data includes data on the production process, company location, number of workers and working hours.

After all the required data is obtained. Then the data will be processed in the following steps:

1. Weighting the results of the questionnaire that has been given to operators to be used as research samples.

2. Calculating the percentage of pain felt in his body based on the Nordic body map questionnaire. The percentage is used to identify the body parts that experience pain during work activities.

3. Calculating the moment and force on the worker.

a. Style On The Right Hand.

Farm1 $=\left[\left(\right.\right.$ Wla1 $x\left(\right.$ Lla1 $\sin ^{\circ}+$ Lua $1 \sin ^{\circ}+$ Lbdn $\left.\left.\sin ^{\circ}\right)\right)+\left(\right.$ Wua1 $x\left(\right.$ Lua1 $\sin ^{\circ}+$ Lbdn $\left.\left.\sin ^{\circ}\right)\right)+($ Warm2 $x\left(\operatorname{Larm} 2 \sin ^{\circ}+\right.$ Lla $2 \sin ^{\circ}+$ Lua2 $\left.\left.\sin ^{\circ}+\operatorname{Lbdn} \sin ^{\circ}\right)\right)+\left(\right.$ Wla2 $x\left(\right.$ Lla2 $\sin ^{\circ}+$ Lua2 $\sin ^{\circ}+$ Lbdn $\left.\left.\sin ^{\circ}\right)\right)+$ $\left(\right.$ Wua2 $x\left(\right.$ Lua2 $\left.\left.\sin ^{\circ}+\operatorname{Lbdn} \sin ^{\circ}\right)\right)+\left(\operatorname{Wbdn} x \operatorname{Lbdn} \sin ^{\circ}\right)+2\left(\right.$ Wthigh $x$ Lthigh $\left.\sin ^{\circ}\right)+2\left(\right.$ Ws $x\left(\right.$ Ls $^{\circ} \sin ^{\circ}+$ Lthigh $\left.\left.\sin ^{\circ}\right)\right)+1 / 2\left(\right.$ Wbeban1 $x\left(\operatorname{Larm} 1 \sin ^{\circ}+\right.$ L1a1 $\sin ^{\circ}+$ Lua1 $\left.\left.\sin ^{\circ}+\operatorname{Lbdn} \sin ^{\circ}\right)\right)+1 / 2($ Wbeban2 $x$ $\left.\left.\left(\operatorname{Larm} 2 \sin ^{\circ}+\operatorname{Lla} 2 \sin ^{\circ}+\operatorname{Lua} 2 \sin ^{\circ}+\operatorname{Lbdn} \sin ^{\circ}\right)\right)\right] /\left(\operatorname{Larm} 1 \sin ^{\circ}+\operatorname{L} 1 \mathrm{a} 1 \sin ^{\circ}+\right.$ Lua $1 \sin ^{\circ}+\operatorname{Lbdn} \sin ^{\circ}$ )

b. Style On the Right Forearm

Fla1 $=\left[\left(\right.\right.$ Warm1 $x\left(\right.$ Larm $1 \sin ^{\circ}+$ L1a1 $\sin ^{\circ}+$ Lua1 $\left.\left.\sin ^{\circ}+\operatorname{Lbdn} \sin ^{\circ}\right)\right)+\left(\right.$ Wua1 $x\left(\right.$ Lua1 $\sin ^{\circ}+$ Lbdn $\sin ^{\circ}$ 
)$)+\left(\right.$ Warm $2 \times\left(\right.$ Larm $2 \sin ^{\circ}+$ Lla2 $\sin ^{\circ}+$ Lua2 $\sin ^{\circ}+$ Lbdn $\left.\left.\sin ^{\circ}\right)\right)+\left(\right.$ Wla2 $x\left(\right.$ Lla2 $\sin ^{\circ}+$ Lua $2 \sin ^{\circ}+$ Lbdn $\left.\left.\sin ^{\circ}\right)\right)+\left(\right.$ Wua2 $x\left(\right.$ Lua2 $\left.\left.\sin ^{\circ}+\operatorname{Lbdn} \sin ^{\circ}\right)\right)+\left(\right.$ Wbdn $x+$ Lthigh $\left.\left.\sin ^{\circ}\right)\right)+1 / 2($ Wbeban1 $x($ Larm 1 $\sin ^{\circ} 15^{\circ}+$ L1a $1 \sin ^{\circ}+$ Lua $\left.\left.1 \sin ^{\circ}+\operatorname{Lbdn} \sin ^{\circ}\right)\right)+1 / 2\left(\right.$ Wbeban2 $x\left(\right.$ Larm $2 \sin ^{\circ}+$ Lla2 $\sin ^{\circ}+$ Lua2 $\sin ^{\circ}$ + Lbdn $\left.\left.\left.\sin ^{\circ}\right)\right)\right] /\left(\right.$ L1a1 $\sin ^{\circ}+$ Lua1 $\sin ^{\circ}+$ Lbdn $\left.\sin ^{\circ}\right)$.

c. Style On Right Upper Arm.

Fua1 $=\left[\left(\right.\right.$ Warm1 $x\left(\right.$ Larm1 $\sin ^{\circ}+$ L1a1 $\sin ^{\circ}+$ Lua1 $\sin ^{\circ}+$ Lbdn $\left.\left.\sin ^{\circ}\right)\right)+\left(\right.$ W1a1 $x\left(L 1 a 1 \sin ^{\circ}+\right.$ Lua1 $\left.\left.\sin ^{\circ}+\operatorname{Lbdn} \sin ^{\circ}\right)\right)+\left(\right.$ Warm $2 \times\left(\operatorname{Larm} 2 \sin ^{\circ}+\right.$ Lla2 $2 \sin ^{\circ}+$ Lua2 $\left.\left.\sin ^{\circ}+\operatorname{Lbdn} \sin ^{\circ}\right)\right)+\left(\right.$ Wla2 $x\left(\right.$ Lla2 $\sin ^{\circ}+$ Lua2 $\left.\left.\sin ^{\circ}+\operatorname{Lbdn} \sin ^{\circ}\right)\right)+\left(\right.$ Wua2 $\left.x\left(\operatorname{Lua} 2 \sin ^{\circ}+\operatorname{Lbdn} \sin ^{\circ}\right)\right)+\left(\right.$ Wbdn $\left.x \operatorname{Lbdn} \sin ^{\circ}\right)+2($ Wthigh $x$ Lthigh $\left.\sin ^{\circ}\right)+2\left(\right.$ Ws $x\left(\right.$ Ls $\sin ^{\circ}+$ Lthigh $\left.\left.\sin ^{\circ}\right)\right)+1 / 2\left(\right.$ Wbeban1 $x\left(\right.$ Larm $1 \sin ^{\circ}+$ L1a1 $\sin ^{\circ}+$ Lua1 $\sin ^{\circ}+$ Lbdn $\left.\left.\sin ^{\circ}\right)\right)+1 / 2\left(\right.$ Wbeban2 $x\left(\operatorname{Larm} 2 \sin ^{\circ}+\right.$ Lla2 $\sin ^{\circ}+$ Lua2 $\left.\left.\left.\sin ^{\circ}+\operatorname{Lbdn} \sin ^{\circ}\right)\right)\right] /\left(\right.$ Lua1 $\sin ^{\circ}+$ Lbdn $\left.\sin ^{\circ}\right)$.

d. Left Hand Style.

Farm2 $=\left[\left(\right.\right.$ Warm1 $x\left(\right.$ Larm1 $\sin ^{\circ}+$ L1a1 $\sin ^{\circ}+$ Lua1 $\sin ^{\circ}+$ Lbdn $\left.\left.\sin ^{\circ}\right)\right)+\left(\right.$ W1a1 $x\left(\right.$ L1a1 $\sin ^{\circ}+$ Lua1 $\left.\left.\sin ^{\circ}+\operatorname{Lbdn} \sin ^{\circ}\right)\right)+\left(\right.$ Wua1 $x\left(\right.$ Lua1 $\left.\left.\sin ^{\circ}+\operatorname{Lbdn} \sin ^{\circ}\right)\right)+\left(\right.$ Wla2 $x\left(\right.$ Lla2 $\sin ^{\circ}+$ Lua2 $\sin ^{\circ}+$ Lbdn $\left.\left.\sin ^{\circ}\right)\right)$ $+\left(\right.$ Wua2 $x\left(\right.$ Lua $\left.\left.2 \sin ^{\circ}+\operatorname{Lbdn} \sin ^{\circ}\right)\right)+\left(\right.$ Wbdn $x$ Lbdn $\left.\sin ^{\circ}\right)+2\left(\right.$ Wthigh $x$ Lthigh $\left.\sin ^{\circ}\right)+2\left(\right.$ Ws $x\left(\right.$ Ls $\sin ^{\circ}$ + Lthigh $\left.\left.\sin ^{\circ}\right)\right)+1 / 2\left(\right.$ Wbeban1 $x\left(\operatorname{Larm} 1 \sin ^{\circ}+\right.$ L1a1 $\sin ^{\circ}+$ Lua1 $\sin ^{\circ}+$ Lbdn $\left.\left.\sin ^{\circ}\right)\right)+1 / 2($ Wbeban2 $\left.\left.x\left(\operatorname{Larm} 2 \sin ^{\circ}+\operatorname{Lla} 2 \sin ^{\circ}+\operatorname{Lua} 2 \sin ^{\circ}+\operatorname{Lbdn} \sin ^{\circ}\right)\right)\right] /\left(\operatorname{Larm} 2 \sin ^{\circ}+\right.$ Lla $2 \sin ^{\circ}+$ Lua $2 \sin ^{\circ}+$ Lbdn $\sin ^{\circ}$ )

e. The Force On The Left Forearm

Fla2 $=\left[\left(\right.\right.$ Warm1 $x\left(\right.$ Larm1 $\sin ^{\circ}+$ L1a1 $\sin ^{\circ}+$ Lua1 $\sin ^{\circ}+$ Lbdn $\left.\left.\sin ^{\circ}\right)\right)+\left(\right.$ W1a1 $x\left(L 1 a 1 \sin ^{\circ}+\right.$ Lua1 $\left.\left.\sin ^{\circ}+\operatorname{Lbdn} \sin ^{\circ}\right)\right)+\left(\right.$ Wua1 $x\left(\right.$ Lua1 $\left.\left.\sin ^{\circ}+\operatorname{Lbdn} \sin ^{\circ}\right)\right)+\left(\right.$ W arm2 $x\left(\right.$ Larm2 $\sin ^{\circ}+$ Lla2 $\sin ^{\circ}+$ Lua2 $\sin ^{\circ}$ + Lbdn $\left.\left.\sin ^{\circ}\right)\right)+\left(\right.$ Wua2 $x\left(\right.$ Lua2 $\sin ^{\circ}+$ Lbdn $\left.\left.\sin ^{\circ}\right)\right)+\left(\right.$ Wbdn $x$ Lbdn $\left.\sin ^{\circ}\right)+2\left(\right.$ Wthigh $x$ Lthigh $\left.\sin ^{\circ}\right)+$ $2\left(\right.$ Ws $x\left(\operatorname{Lss}^{\circ} \sin ^{\circ}+\right.$ Lthigh $\left.\left.\sin ^{\circ}\right)\right)+1 / 2\left(\right.$ Wbeban1 $x\left(\operatorname{Larm} 1 \sin ^{\circ}+\right.$ L1a $1 \sin ^{\circ}+$ Lua $1 \sin ^{\circ}+$ Lbdn $\left.\left.\sin ^{\circ}\right)\right)$ $+1 / 2\left(\right.$ Wbeban $2 \times\left(\right.$ Larm $2 \sin ^{\circ}+$ Lla2 $\sin ^{\circ}+$ Lua2 $\sin ^{\circ}+$ Lbdn $\left.\left.\left.\sin ^{\circ}\right)\right)\right] /\left(\right.$ Lla2 $\sin ^{\circ}+$ Lua2 $\sin ^{\circ}+$ Lbdn $\left.\sin ^{\circ}\right)$

f. Style On Left Upper Arm

Fua2 $=\left[\left(\right.\right.$ Warm1 $x\left(\right.$ Larm1 $\sin ^{\circ}+\mathrm{L} 1 \mathrm{a} 1 \sin ^{\circ}+$ Lua1 $\sin ^{\circ}+$ Lbdn $\left.\left.\sin ^{\circ}\right)\right)+\left(\right.$ W1a1 $x\left(L 1 a 1 \sin ^{\circ}+\right.$ Lua1 $\left.\left.\sin ^{\circ}+\operatorname{Lbdn} \sin ^{\circ}\right)\right)+\left(\right.$ Wua1 $x\left(\right.$ Lua1 $\left.\left.\sin ^{\circ}+\operatorname{Lbdn} \sin ^{\circ}\right)\right)+\left(\right.$ W $\operatorname{arm} 2 \times\left(\right.$ Larm $2 \sin ^{\circ}+$ Lla2 $\sin ^{\circ}+$ Lua2 $\sin ^{\circ}$ + Lbdn $\left.\left.\sin ^{\circ}\right)\right)+\left(\right.$ W la $2 \times\left(\right.$ Lla $2 \sin ^{\circ}+$ Lua2 $\sin ^{\circ}+$ Lbdn $\left.\left.\sin ^{\circ}\right)\right)+\left(\right.$ Wbdn $x$ Lbdn $\left.\sin ^{\circ}\right)+2($ Wthigh $x$ Lthigh $\left.\sin ^{\circ}\right)+2\left(\right.$ Ws $x\left(\right.$ Ls $\sin ^{\circ}+$ Lthigh $\left.\left.\sin ^{\circ}\right)\right)+1 / 2\left(\right.$ Wbeban1 $x\left(\right.$ Larm $1 \sin ^{\circ}+$ L1a1 $\sin ^{\circ}+$ Lua1 $\sin ^{\circ}+$ Lbdn $\left.\left.\sin ^{\circ}\right)\right)+1 / 2\left(\right.$ Wbeban $2 x\left(\operatorname{Larm} 2 \sin ^{\circ}+\right.$ Lla2 $\sin ^{\circ}+$ Lua2 $\left.\left.\left.\sin ^{\circ}+\operatorname{Lbdn} \sin ^{\circ}\right)\right)\right] /\left(\right.$ Lua2 $\sin ^{\circ}+$ Lbdn $\left.\sin ^{\circ}\right)$

g. Style on the body

Fbdn $=\left[\left(\right.\right.$ Warm1 $x\left(\right.$ Larm1 $\sin ^{\circ}+$ L1a1 $\sin ^{\circ}+$ Lua1 $\sin ^{\circ}+$ Lbdn $\left.\left.\sin ^{\circ}\right)\right)+\left(\right.$ W1a1 $x\left(\right.$ L1a1 $\sin ^{\circ}+$ Lua 1 $\left.\left.\sin ^{\circ}+\operatorname{Lbdn} \sin ^{\circ}\right)\right)+\left(\right.$ Wua1 $x\left(\right.$ Lua1 $\left.\left.\sin ^{\circ}+\operatorname{Lbdn} \sin ^{\circ}\right)\right)+\left(\right.$ W $\operatorname{arm} 2 \times\left(\operatorname{Larm} 2 \sin ^{\circ}+\right.$ Lla2 $2 \sin ^{\circ}+$ Lua2 $\sin ^{\circ}$ + Lbdn $\left.\left.\sin ^{\circ}\right)\right)+\left(\right.$ W la2 $x\left(\right.$ Lla $2 \sin ^{\circ}+$ Lua2 $\left.\left.\sin ^{\circ}+\operatorname{Lbdn} \sin ^{\circ}\right)\right)+\left(\right.$ Wua2 $x\left(\right.$ Lua2 $\sin ^{\circ}+$ Lbdn $\left.\left.\sin ^{\circ}\right)\right)+$ $2\left(\right.$ Wthigh $x$ Lthigh $\left.\sin ^{\circ}\right)+2\left(\right.$ Ws $x\left(\right.$ Ls $\sin ^{\circ}+$ Lthigh $\left.\left.\sin ^{\circ}\right)\right)+1 / 2\left(\right.$ Wbeban $1 \times\left(\right.$ Larm $1 \sin ^{\circ}+$ L1a1 $\sin ^{\circ}$ + Lua1 $\left.\left.\sin ^{\circ}+\operatorname{Lbdn} \sin ^{\circ}\right)\right)+1 / 2\left(\right.$ Wbeban2 $x\left(\operatorname{Larm} 2 \sin ^{\circ}+\right.$ Lla2 $\sin ^{\circ}+$ Lua2 $\sin ^{\circ}+$ Lbdn $\left.\left.\left.\sin ^{\circ}\right)\right)\right] /$ Lbdn $\sin ^{\circ}$

h. Style On Thigh (Thigh)

Fthigh $=\left[\left(\right.\right.$ Warm1 $x\left(\right.$ Larm $1 \sin ^{\circ}+$ L1a1 $\sin ^{\circ}+$ Lua1 $\sin ^{\circ}+$ Lbdn $\left.\left.\sin ^{\circ}\right)\right)+\left(\right.$ W1a1 $\times\left(L 1 a 1 \sin ^{\circ}+\right.$ Lua1 $\left.\left.\sin ^{\circ}+\operatorname{Lbdn} \sin ^{\circ}\right)\right)+\left(\right.$ Wua1 $x\left(\right.$ Lua $\left.\left.1 \sin ^{\circ}+\operatorname{Lbdn} \sin ^{\circ}\right)\right)+\left(\right.$ Warm $2 \times\left(\operatorname{Larm} 2 \sin ^{\circ}+\right.$ Lla2 $\sin ^{\circ}+$ Lua2 $\sin ^{\circ}$ + Lbdn $\left.\left.\sin ^{\circ}\right)\right)+\left(\right.$ Wla2 $x\left(\right.$ Lla2 $\sin ^{\circ}+$ Lua2 $\sin ^{\circ}+$ Lbdn $\left.\left.\sin ^{\circ}\right)\right)+\left(\right.$ Wua2 $x\left(\right.$ Lua2 $\sin ^{\circ}+$ Lbdn $\left.\left.\sin ^{\circ}\right)\right)+($ Wbdn $x$ Lbdn $\left.\sin ^{\circ}\right)+2\left(\right.$ Ws $x\left(\right.$ Ls $\sin ^{\circ}+$ Lthigh $\left.\left.\sin ^{\circ}\right)\right)+1 / 2\left(\right.$ Wbeban1 $x\left(\operatorname{Larm} 1 \sin ^{\circ}+\right.$ L1a $1 \sin ^{\circ}+$ Lua1 $\sin ^{\circ}$ $\left.\left.+\operatorname{Lbdn} \sin ^{\circ}\right)\right)+1 / 2\left(\right.$ Wbeban2 $\left.\left.x\left(\operatorname{Larm} 2 \sin ^{\circ}+\operatorname{Lla} 2 \sin ^{\circ}+\operatorname{Lua} 2 \sin ^{\circ}+\operatorname{Lbdn} \sin ^{\circ}\right)\right)\right] / 2$ Lthigh $\sin ^{\circ}$

i. Style On Shank (Calf)

Fs $=\left[\left(\right.\right.$ Warm $1 \times\left(\right.$ Larm $1 \sin ^{\circ}+$ L1a $1 \sin ^{\circ}+$ Lua1 $\sin ^{\circ}+$ Lbdn $\left.\left.\sin ^{\circ}\right)\right)+\left(\right.$ W1a1 $x\left(L 1 a 1 \sin ^{\circ}+\right.$ Lua $1 \sin ^{\circ}$ + Lbdn $\left.\left.\sin ^{\circ}\right)\right)+\left(\right.$ Wua1 $x\left(\right.$ Lua1 $\left.\left.\sin ^{\circ}+\operatorname{Lbdn} \sin ^{\circ}\right)\right)+\left(\right.$ Warm $2 \times\left(\operatorname{Larm} 2 \sin ^{\circ}+\right.$ Lla2 $2 \sin ^{\circ}+$ Lua2 $\sin ^{\circ}+$ Lbdn $\left.\left.\sin ^{\circ}\right)\right)+\left(\right.$ Wla2 $x\left(\right.$ Lla $2 \sin ^{\circ}+$ Lua2 $\left.\left.\sin ^{\circ}+\operatorname{Lbdn} \sin ^{\circ}\right)\right)+\left(\right.$ Wua2 $x\left(\right.$ Lua2 $\sin ^{\circ}+$ Lbdn $\left.\left.\sin ^{\circ}\right)\right)+($ Wbdn $x$ Lbdn $\left.\sin ^{\circ}\right)+2\left(\right.$ Wthigh $x$ Lthigh $\left.\sin ^{\circ}\right)+1 / 2\left(\right.$ Wbeban1 $x\left(\right.$ Larm $1 \sin ^{\circ}+$ L1a1 $\sin ^{\circ}+$ Lua1 $\sin ^{\circ}+$ Lbdn $\left.\left.\sin ^{\circ}\right)\right)+1 / 2\left(\right.$ Wbeban2 $x\left(\operatorname{Larm} 2 \sin ^{\circ}+\right.$ Lla2 $\sin ^{\circ}+$ Lua2 $\sin ^{\circ}+$ Lbdn $\left.\left.\left.\sin ^{\circ}\right)\right)\right] / 2\left(\right.$ Ls $\sin ^{\circ}+$ Lthigh $\left.\sin ^{\circ}\right)$

4. Perform employee anthropometric calculations to determine the dimensions of the new work facility.

5. Designing work facility proposals based on predetermined criteria

6. Calculating the force that occurs in workers' work elements after designing new work facilities. 


\section{RESULT AND DISCUSION}

UD.Usaha Muda is a business engaged in the production of bricks, whose production process is still carried out traditionally with 5 workers in the entire production site and 2 workers in the molding process. While the location of UD. Usaha Muda is located in Gampong Ule Pulo, Dewantara District, Kab. North Aceh. The working hours are 08.00-16.00 WIB.

The work facilities found in a young brick printing company can be seen in table 1. as follows.

\section{Table 1. Work Facilities}

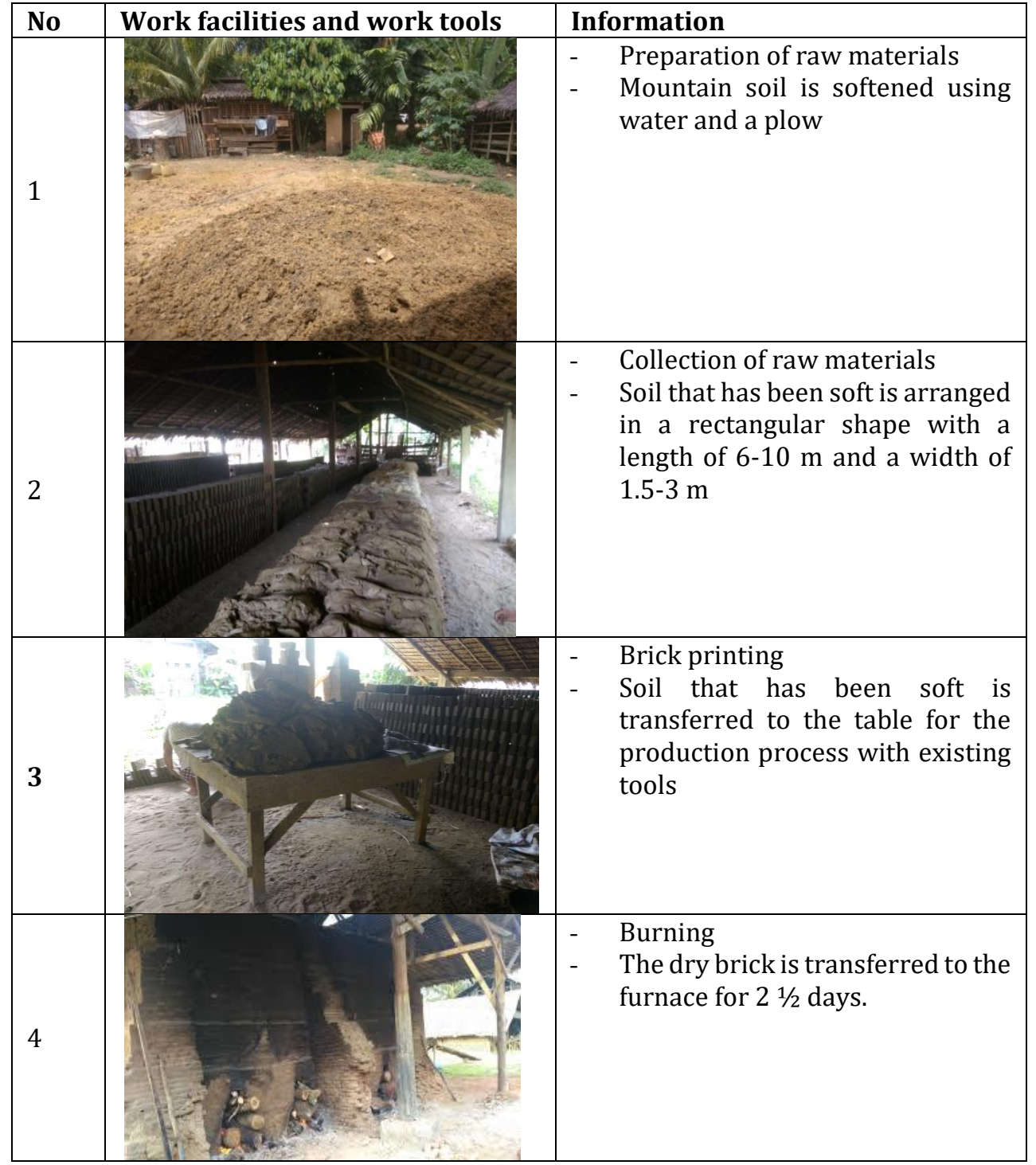

In this study, the work facility observed at UD .Usaha Muda is the brick-molding process, at this stage it can be said the essence of the brick production process.

In this study, the focus of research is the work posture of bricklaying, while the observed work posture can be seen in table 2 below. 
Table 2. Bricks Printing work posture

\begin{tabular}{|l|l|}
\hline work description & Workers coat the press with sand to prevent \\
\hline Woil from sticking to the mold
\end{tabular}

The results of data processing on the magnitude of the force that occurs in the worker body segment 1 can be seen in table 3 . 
Table 3. Recapitulation of Style in Workers 1

\begin{tabular}{|l|l|l|l|l|}
\hline \multirow{2}{*}{$\begin{array}{l}\text { Segment } \\
\text { Body }\end{array}$} & \multicolumn{4}{|l|}{ Work Activities } \\
\cline { 2 - 5 } & $\begin{array}{l}\text { Mold } \\
\text { Coating (N) }\end{array}$ & $\begin{array}{l}\text { Land } \\
\text { Acquisition } \\
\text { (N) }\end{array}$ & $\begin{array}{l}\text { Printing Process } \\
\text { (N) }\end{array}$ & $\begin{array}{l}\text { Moving Bricks } \\
\text { (N) }\end{array}$ \\
\hline Hand & 151,69 & 156,98 & 160,79 & 175,19 \\
\hline Forearm & 184,16 & 166,48 & 165,68 & 251,38 \\
\hline Upper arm & 232,31 & 284,97 & 286,68 & 269,24 \\
\hline Body / waist & 348,42 & 353,04 & 429,94 & 180,97 \\
\hline Thigh & 306,49 & 299,63 & 262,11 & 719,82 \\
\hline Calf & 242,46 & 293,34 & 285,93 & 368,18 \\
\hline
\end{tabular}

Meanwhile, to facilitate the preparation of data processing research reports for each work element can be seen in appendix 2. In processing worker data 1 in table 3 for the body segment of the hands, the average value of both hands is used, the same thing is done on the upper and lower arms. Meanwhile, the results of the body segments of the body.

The following is a table of recapitulation of work activity styles performed by workers 2 .

Table 4. Style recapitulation of workers 2

\begin{tabular}{|l|l|l|l|l|}
\hline \multirow{2}{*}{$\begin{array}{l}\text { Segment } \\
\text { Body }\end{array}$} & \multicolumn{4}{|l|}{ Work Activities } \\
\cline { 2 - 5 } & $\begin{array}{l}\text { Mold } \\
\text { Coating (N) }\end{array}$ & $\begin{array}{l}\text { Land } \\
\text { Acquisition } \\
\text { (N) }\end{array}$ & $\begin{array}{l}\text { Mold Coating } \\
\text { (N) }\end{array}$ & $\begin{array}{l}\text { Moving } \\
\text { Bricks (N) }\end{array}$ \\
\hline Hand & 166,33 & 153,1 & 160,64 & 176,44 \\
\hline Forearm & 202,72 & 173,53 & 165,68 & 197,38 \\
\hline Upper arm & 281,69 & 308,95 & 286,68 & 275,62 \\
\hline Body / waist & 364,82 & 476,9 & 429,94 & 184,29 \\
\hline Thigh & 249,64 & 191,48 & 262,11 & 726,95 \\
\hline Calf & 135,48 & 154,87 & 285,93 & 514,57 \\
\hline
\end{tabular}

In data processing worker 2 for the body segment of the hand, the final result used is the average value of the two body segments on the work element of the worker 2 mold coating has a value of $166.33 \mathrm{~N}$, for the forearm $202.72 \mathrm{~N}$, the upper arm 281, $69 \mathrm{~N}$. As for the processing results on the body body segment $364.82 \mathrm{~N}$, the body segment of the thigh is $249.64 \mathrm{~N}$ and the calf is $135.48 \mathrm{~N}$.

The redesign of the work facility (Printing Desk) will directly improve the working posture of the operator using the tool. Redesign of work facilities based on anthropometric data, standing elbow height with 5th percentile, shoulder width with 5th percentile, and shoulder width with 95th percentile, as follows:

a. Elbow Height stands at the 5 th percentile

$\mathrm{P} 5=\mathrm{x}-1,645 \sigma \mathrm{xs}$

$\mathrm{P} 5=96.4-(1.645 \times 2.09)$

P5 $=92.9 \mathrm{~cm}$

b. The length of the arm reach forward with the 5 th percentile

$\mathrm{P} 5=\mathrm{x}-1,645 \sigma \mathrm{x}$

$\mathrm{P} 5=40.15-(1.645 \times 0.35)$

$\mathrm{P} 5=39.58=40 \mathrm{~cm}$

c. 95th percentile shoulder width

$\mathrm{P} 95=\mathrm{x}+1,645 \sigma \mathrm{x}$

$\mathrm{P} 95=39.8+(1.645 \times 0.22)$

P95 $=40.1 \mathrm{~cm}$

Worker's position on the print table design is measured based on the standing elbow height with the 5th percentile so that the short posture can adjust the table height to the minimum height, the reach of the hands forward with the 5th percentile so that short arm reach can reach the minimum height, shoulder width uses 
the 95th percentile with the aim that operators with the greatest shoulder width can comfortably carry out brick molding activities.

After the anthropometric calculations of the workers are carried out, the new work facility is designed using AutoCad Software. Work facility planning activities are carried out in the brick-molding process. This design is very much needed because seen from the results of the complaints from the Nordic Body Map (NBM) questionnaire, it caused several mosculoskeletal complaints from the work carried out by workers. The design of this new work facility is proposed to reduce complaints of pain that occurs in the workers' muscles.

The proposed work facilities are in the form of a production table and a drying place for the newly produced bricks. The design of this work facility is based on anthropometric data from each worker, namely standing elbow height for work facility height, arm length for the width of the work facility, and shoulder width. Figure of proposed work facilities can be seen in table 5 below:

Table 5. Drawing of Work Facilities

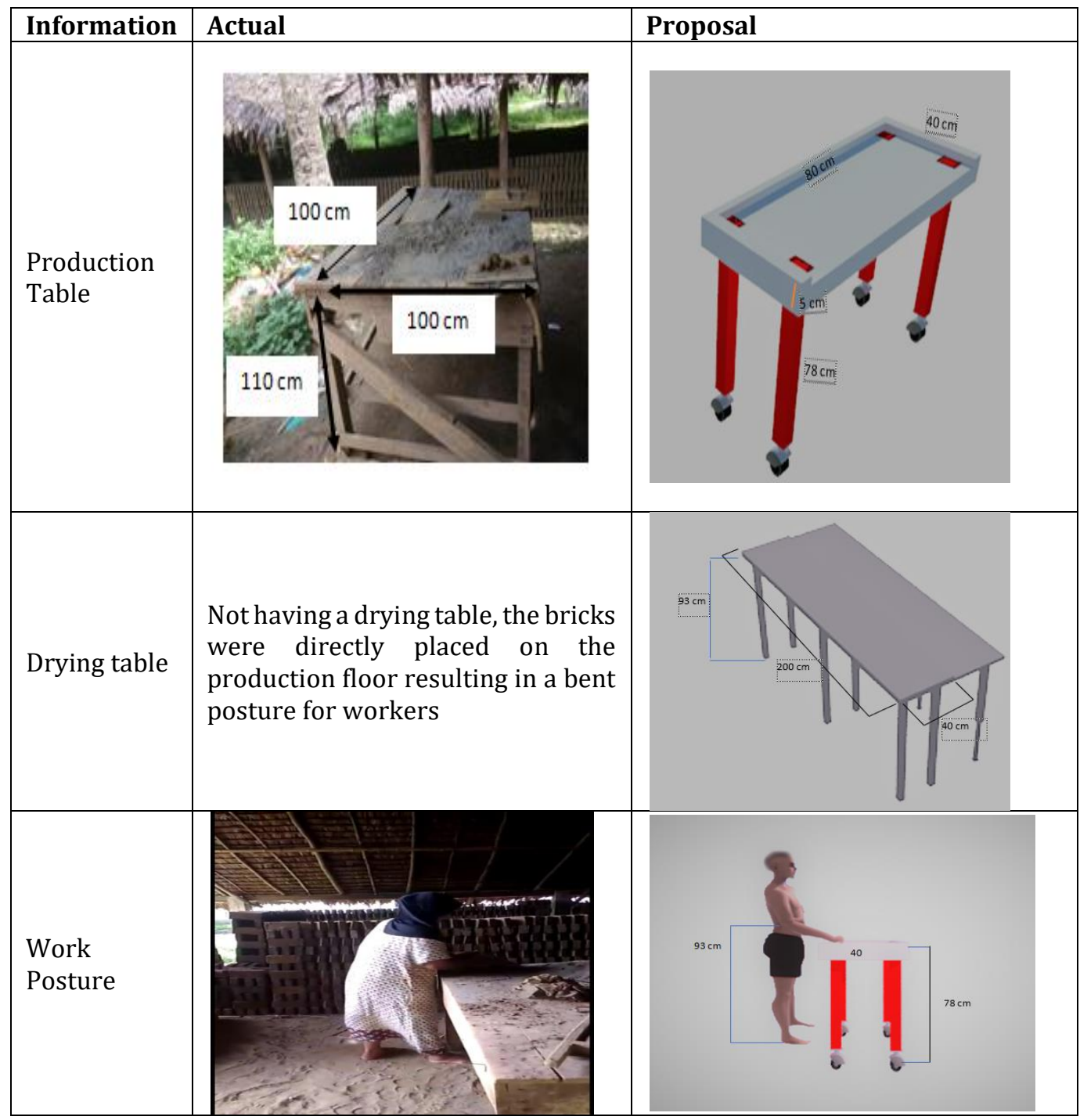

\section{CONCLUSION}

The conclusions that can be drawn from the writing of this study are as follows:

1. Assessment of work posture in brick-molding activities with a biomechanical approach to assessing the force that occurs in each segment, causing a large force on average on the body, thight, and shank segments. 
This shows that the existing work facilities are less ergonomic and cause complaints. pain in every segment of the worker's body.

2. Improved work facilities for the brick printing section of the printing table in the form of a temporary drying table in order to reduce bending movements for brick-press workers. On the table, wheels and walls are provided so that the sand does not drastically decrease during the printing process, and the wheel functions so that workers can easily move the table to pick up clay that has been arranged in other work facilities.

\section{REFERENCES}

Chaffin dan Anderson (1984), "occupacional biomechanics" (books.google.com)

Catur Setiawan. Muhammad (2012), "Perbaikan postur kerja dengan merancang ulang meja printing menggunakan metode REBA dan pendekatan biomekanik" (scholar.google.co.id)

Bridger (1995) "Kerja otot dan Kerja statis" (puslit2.petra.ac.id)

Hawkins (1987),“Tujuan praktis ergonomi” (https://tugasmahasiswateknik99.blogspot.com)

Iftukar Z, Sutalaksana (2006),Teknik Perancangan Sistem Kerja. Bandung. ITB

Hayati. Zen Zayyinul.(2014) "Perancangan Alat Material Handling Dengan Menggunakan Pendekatan Biomekanika Dan Postur Kerja Pada Bagian Pengepakan Pupuk" (scholar.google.co.id).

Nurhayati. Dyah (2010) dengan judul "Analisa Beban Tas Siswa Sekolah Dasar Berdasarkan Aspek BiomekanikaSebagai Bahan Pertimbangan Dalam Desain" (scholar.google.co.id)

Prastowo. Hary (2010), "Assesment biomekanika pada perancangan alat bantu untuk perbaikan postur tubuh pekerja penghalusa benda kerja pulley di stasiun kerja finishing" (scholar.google.co.id)

Raven (2002). "Sistem otot terdiri atas" (https://anzdoc.com)

Saragih. Rahmadan Syah (2015) "Analisis Biomekanika pada Pekerja Pemanen Kelapa Sawit dengan Egrek di PT. Perkebunan Nusantara III (Kebun Rambutan)” (http://repository.usu.ac.id).

Waters \& Bhattacharya (1996). "Kekuatan otot otot" (https://text-id.123dok.com) 